\title{
Predictive Value of Cerebrospinal Fluid Lactate Level for the Diagnosis of Bacterial Meningitis following Cranial Surgery
}

\author{
Ashok Kharel $M S^{1}$ iD, Gopal Sedain $M C h^{2}$ iD, Sushil Krishna Shilpakar $M S^{3}$ iD, Mohan Raj Sharma $M S^{4}$ iD \\ ${ }^{1}$ Department of Surgery, Narayani Samudayik Hospital, Chitwan, Nepal \\ ${ }^{2,3,4}$ Department of Neurosurgery, Institute of Medicine, Kathmandu, Nepal
}

Date of submission: $19^{\text {th }}$ May 2021

Date of acceptance: $31^{\text {st }}$ October 2021

Date of publication: $1^{\text {st }}$ December 2021

\section{Abstract}

Introduction: To distinguish post-neurosurgical bacterial meningitis (PNBM) from aseptic meningitis is difficult. Inflammatory and biochemical cerebrospinal fluid (CSF) changes mimic those classically observed after CNS surgery. Cerebrospinal fluid lactate assay has therefore been proposed as a useful PNBM marker.

Methods and Materials: Between January 2016 and December 2016, a prospective clinical study was done at the Department of Neurosurgery, in which all patients with clinical suspicion of post-neurosurgical bacterial meningitis were enrolled. Patients with clinical suspicion of bacterial meningitis (BM) were categorized, according to preset criteria, into three groups: (1) proven BM; (2) presumed BM, and (3) non-bacterial meningeal syndrome (NBMS). Cerebrospinal fluid markers were plotted in a receiver operating curve (ROC) to evaluate their diagnostic accuracy. Results: The study included seventy patients. Sixty five cerebrospinal fluid samples from patients with clinical suspicion of BM by cerebrospinal fluid analysis. Twenty corresponded to proven BM, 7 to presumed BM and 38 to excluded BM. Mean lactate in cerebrospinal fluid was: $8.4 \pm 3.0 \mathrm{mmol} / 1$ for proven BM, $4.8 \pm 0.99 \mathrm{mmol} / 1$ for presumed and $2.08 \pm 0.822 \mathrm{mmol} / \mathrm{l}$ for non-bacterial meningeal syndrome $(P<.001)$.

Conclusion: Cerebrospinal fluid lactate level has good predictive value to distinguish BM from (Non-bacterial meningeal syndrome) with sensitivity of $90 \%$ and specificity of $87 \%$ at cut-off value of $4.0 \mathrm{mmol} / 1$.

Key words: Aseptic meningitis, Bacterial meningitis, CSF lactate.

\section{Introduction}

$\mathrm{T}^{\mathrm{m}}$ he occurrence of meningitis after neurosurgical procedures is uncommon, with an estimated incidence between $0.3 \%$ and $1.5 \%$ following different neurosurgical interventions. ${ }^{1}$

Access this article online
Website: https://www.nepjol.info/index.php/NJN
DOI: https://doi.org/10.3126/njn.v18i4.31171
HOW TO CITE
Kharel A, Sedain G, Shilpakar SK, Sharma MR. Predictive Value
of Cerebrospinal Fluid Lactate Level for the Diagnosis of Bacterial
Meningitis following Cranial Surgery. NJNS. 2021;18(4):12-8.

Address for correspondence:

Dr. Gopal Sedain

Department of Neurosurgery,

Institute of Medicine,

Maharajgunj, Kathmandu, Nepal.

E-mail: newron79@gmail.com

Phone: +9779849485319

Copyright (C) 2021 Nepalese Society of Neurosurgeons (NESON)

ISSN: 1813-1948 (Print), 1813-1956 (Online)

This work is licensed under a Creative Commons Attribution-Non Commercial 4.0 International License.
However, it remains a significant problem associated with high morbidity, and reported mortality rates range between $20 \%$ and $50 \% .^{2}$ Diagnosis is sometimes difficult, because the clinical manifestations are often mild and nonspecific during the immediate postoperative period. In addition, CSF protein and cell composition are modified by the surgical procedure itself, making it difficult to interpret laboratory results.

The concept of postoperative aseptic meningitis was first described by Cushing but the mechanisms remain unclear. Aseptic meningitis occurs more frequently in children and after surgery involving the posterior fossa, and it may occur as a result of a local inflammatory reaction to blood breakdown products or to tumor antigens. ${ }^{3}$

Aseptic meningitis comprises $60 \%-75 \%$ of all cases of postoperative meningitis. The clinical manifestations and CSF findings associated with aseptic meningitis are very similar to those associated with postoperative bacterial meningitis, and the distinction between the 2 entities is currently based solely on the results of CSF culture. ${ }^{4}$

The diagnosis of bacterial meningitis (BM) is difficult in patients after neurosurgery for several reasons. Meningeal syndrome with a stiff neck, fever, and headache occurs frequently in patients following craniotomy. Blood, surgical manipulation, surgical materials and bone dust appear to trigger inflammatory 
processes mimicking bacterial meningitis CSF changes. Neutrophil CSF pleocytosis can be present in various infectious and non-infectious forms of meningitis as a consequence of subarachnoid-space inflammation..$^{5-7}$ Up to $50 \%$ of patients with clinical signs of meningitis have already been treated with steroids or antibiotics, at the time of lumbar puncture. ${ }^{4,8}$ Standard CSF studies (i.e., gram staining and determinations of leukocyte count and glucose and protein concentration) are unreliable for the diagnosis of BM after neurosurgery. ${ }^{4}$ Therefore, additional CSF parameters that allow differentiation of $\mathrm{BM}$ from nonbacterial meningeal syndrome (NBMS) are needed. The ideal biochemical PNBM marker should be highly sensitive and present for early measurement in the course of infection. CSF lactic acid has been proposed as a potential marker distinguishing between infection and inflammation. ${ }^{9}$ The measurement of CSF lactate by a portable lactate meter similar to a glucometer can give quick results.

CSF lactate in BM originates from different sources. Bacterial pathogens themselves produce varying amounts of lactate, accounting for $10 \%$ of total CSF lactate in patients with BM. ${ }^{6}$ The main source of lactate in BM is brain tissue, including neurons and glia cells, which produce lactate by distinct mechanisms. ${ }^{10} \mathrm{BM}$ is associated with generalized brain edema, causing a reduction of global cerebral blood flow and inflammatory involvement of the vasculature, with loss of auto-regulatory mechanisms, vasospasms, and thrombosis. ${ }^{2,11,12,13}$ This leads to cerebral ischemia and consequently to glycolysis by means of anaerobic metabolism. In addition, cytokines that flood the brain in meningitis reduce tissue oxygen uptake and cause a shift toward anaerobic metabolism, thus increasing lactate production. ${ }^{10,14}$ Because lactate penetrates the blood-brain barrier at a very low rate, measurement of CSF lactate is a useful index of cerebral metabolism. ${ }^{14}$ In addition, cytokines also mediate invasion of neutrophils into the subarachnoid space, which may also contribute to the rise in CSF lactate level by glycolysis. ${ }^{15}$

Recent studies have indicated that CSF lactate shows a certain degree of diagnostic accuracy for differentiating between postoperative bacterial meningitis and aseptic meningitis. ${ }^{16}$ However, no systematic evaluations have investigated this aspect. In recent years, it has been proposed that CSF lactate may be a good marker that can differentiate bacterial meningitis $(>6 \mathrm{mmol} / \mathrm{l})$, from partially treated meningitis (4 to $6 \mathrm{mmol} / \mathrm{l}$ ) and aseptic meningitis $(<2 \mathrm{mmol} / \mathrm{l}) .{ }^{17}$

However, other researchers have suggested that CSF lactate offers no additional clinically useful information over conventional CSF markers. ${ }^{18,19}$ Other markers, such as $\mathrm{C}$-reactive protein $(\mathrm{CRP})^{20}$ and pro-calcitonin ${ }^{21}$, heparinbinding protein ${ }^{22}, \mathrm{sCD} 163^{23}$ may allow differentiation of patients with bacterial meningitis from those with aseptic meningitis. However, neither of these markers is routinely used in clinical practice. The CSF lactate exam is simple, objective and affordable. ${ }^{2}$ The exam is not affected by blood contamination of the CSF. ${ }^{14,22}$ Many researchers also reported that the CSF lactate concentration was not related to the neutrophil count. ${ }^{2,23,24}$ The test can be performed at the bedside, and the results can be received immediately. Additionally, a rapid decrease in the CSF lactate level following antibiotic treatment could suggest a relatively good prognosis. Therefore, CSF lactate may play a significant role in the diagnosis of post-neurosurgical bacterial meningitis. In this study, CSF lactate accuracy for PNBM diagnosis (proven and presumed) was investigated prospectively.

\section{Methods and Materials}

It is a prospective observational study done with purposive sampling. This study was conducted at the Department of Neurosurgery. Ethical clearance was obtained from the Institutional Review Board. Duration of the study was one year. All patients who developed meningeal syndrome following cranial surgery from January 2016 to December 2016 were included in the study after prior informed consent.

CSF analysis of patients who underwent either elective or emergency cranial surgery and developed meningeal syndrome was done. CSF lactate of the same sample was also sent. Patients with clinically suspected $\mathrm{BM}$ were categorized according to the following preset criteria:

(1) For proven BM, a positive bacterial CSF culture and a leukocyte count of $>250 / \mathrm{mL}$

(2) For presumed BM, 1,000 WBCs $/ \mathrm{mL}$ with $>50 \%$ neutrophils or (if the patient was treated with steroids and/or antibiotics at the time of the first lumbar puncture) $>250 \mathrm{WBCs} / \mathrm{mL}$ with $50 \%$ neutrophils

(3) for non-BM(NBMS), a negative CSF culture and $<250 \mathrm{WBCs} / \mathrm{mL}$ with $<50 \%$ neutrophils.

Criteria for the clinical categories were established prior to the evaluation.

Lactate Scout + is a device manufactured by Sens lab (an EKF diagnostic company) from Germany. (Fig 1) It uses disposable lactate sensors to determine the level of lactate in the body fluid. The sample volume needed is $0.2 \mu \mathrm{l}$. The measuring range is $0.5-25 \mathrm{mmol} / \mathrm{l}$. The readings below and above that range are shown as "LO" and "HI" respectively. CSF cytology (TC/ DC) are calculated microscopically. CSF sugar and protein are calculated automatically with Erba Mannheim XL200 using spectrometry.

Clinical parameters examined were age, sex, type of surgery, presence and type of a foreign device, postoperative day on which lumbar puncture was performed, the antibiotic and/or steroid regimen initiated 


\section{Kharel et al}

before and at the time of lumbar puncture, and organism(s) identified by CSF culture.

\section{Inclusion criteria}

Patients suspected of postoperative bacterial meningitis and who underwent CSF analysis within 40 days of surgery were included for our study. Patients who had Sepsis syndrome due to causes other than Bacterial meningitis were excluded from the study.

\section{Sample size:}

The formula for sample size: $\mathbf{n}=\mathbf{z}^{2} \mathbf{p}(\mathbf{1}-\mathbf{p}) / \mathbf{d}^{2}$

$\mathrm{n}=$ required sample size

$\mathrm{z}=$ confidence interval (1.96 for $95 \%$ confidence interval)

$$
\begin{aligned}
& \mathrm{p}=\text { estimated prevalence } \\
& \mathrm{d}=\text { margin of error }(0.05 \text { for } 5 \% \text { error }) \\
& \mathrm{n}=1.96 \times 1.96 \times \mathrm{p} \times(1-\mathrm{p}) / 0.05 \times 0.05=59
\end{aligned}
$$

\section{Statistical Analysis}

Statistical analyses were performed using IBM SPSS 20.0. (IBM Inc., New York, NY). For descriptive statistics, Microsoft word and Excel were used to generate diagrams, graphs and tables. Descriptive statistics of quantitative data were presented as mean and standard deviation. Uni variate analysis was done with the Chi-square test/Fisher exact test. Continuous data were analyzed by One-way ANOVA test. Area under the ROC curve has been used to find the Diagnostic and predictive value of preoperative score for predicting the preoperative outcome based on easy and difficult binary outcome. If $p<0.001$ then the variable was called highly significant, if $p \leq 0.01$ then strongly significant and $0.01<\mathrm{p} \leq 0.05$, then the variable was called moderately significant.

\section{Result}

\section{Demographic characteristics}

The data was collected from January 2016 to December 2016. A total of 65 patients fulfilled the inclusion criteria and thus participated in the study. The median age of the patients in the study was 18 months ranging from 1 month to 70 years. There was female predominance, female $52 \%$ vs. male $47 \%$. Different clinical conditions for which patients were managed have been tabulated in table 1 . Most of the patients were in the pediatric group as the incidence of VP shunt and ensuing infections are high in this group.

The prevalence of bacterial meningitis was 20 $(30.8 \%)$. Non-bacterial meningitis syndrome was seen in $38(58.46 \%)$ and presumed bacterial meningitis in 7 patients (10.76\%). Among 20 confirmed bacterial meningitis patients, Staphylococcus aureus was isolated in 35\%, Klebsiella pneumonia in $20 \%$, Pseudomonas aeruginosa in $15 \%$, Acinetobacter sp. in $10 \%$, Burkholderia sp. in $10 \%$ and Citrobacter freundii in $10 \%$. This shows a trend towards increasing gram negative shunt infections.

\section{Biochemical characteristics}

The CSF analysis revealed that 19 patients with bacterial meningitis had lactate level more than $4 \mathrm{mmol} / \mathrm{L}$ except one who had CSF lactate $2.85 \mathrm{mmol} / \mathrm{l}$. In patients with NMBS, none except one $(4.54 \mathrm{mmol} / \mathrm{L})$ had lactate level $>4 \mathrm{mmol} / \mathrm{l}$. The results of culture, neutrophil count, WBC count, along with culture results and CSF lactate level were documented.

Table 2 presents the correlation between CSF WBC count and CSF lactate level. The result here shows that the CSF lactate level is positively correlated to WBC count as the significance level is $<.0001$ and correlation coefficient is 0.540 . They have a strong positive correlation. $(r=0.40$ to 0.69 )

From the table 3 , we can conclude that CSF lactate level was significantly higher $(\mathrm{p}<0.0001)$ in patients with bacterial meningitis as compared to patients with nonbacterial meningitis syndrome $(p<0.005)$. There was significant difference in the mean CSF lactate level among three groups. (f 79.82, df 2, p<0.001).

\section{ROC Curve}

The area under the curve is 0.96 (table 4) which is in between 0.90 and 1 that indicate the experiment has a very high level of specificity and the significance level is $<0.001$. The cut off point is 4.0 , the sensitivity at that point is $90 \%$ and specificity is $87 \%$. The positive predictive value is $75 \%$ and the negative predictive value is $95.12 \%$.

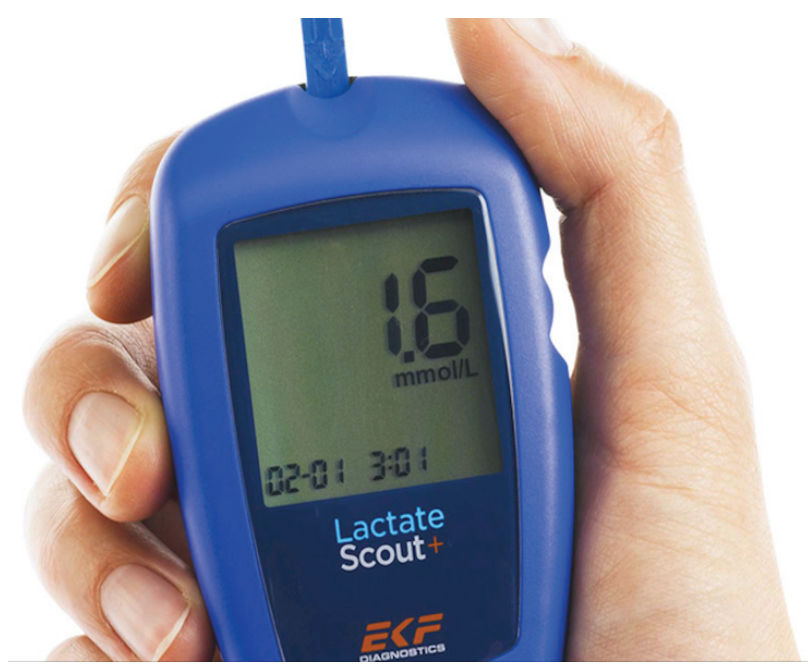

Figure 1: Lactate Scout + machine used to get point of care lactate level. 


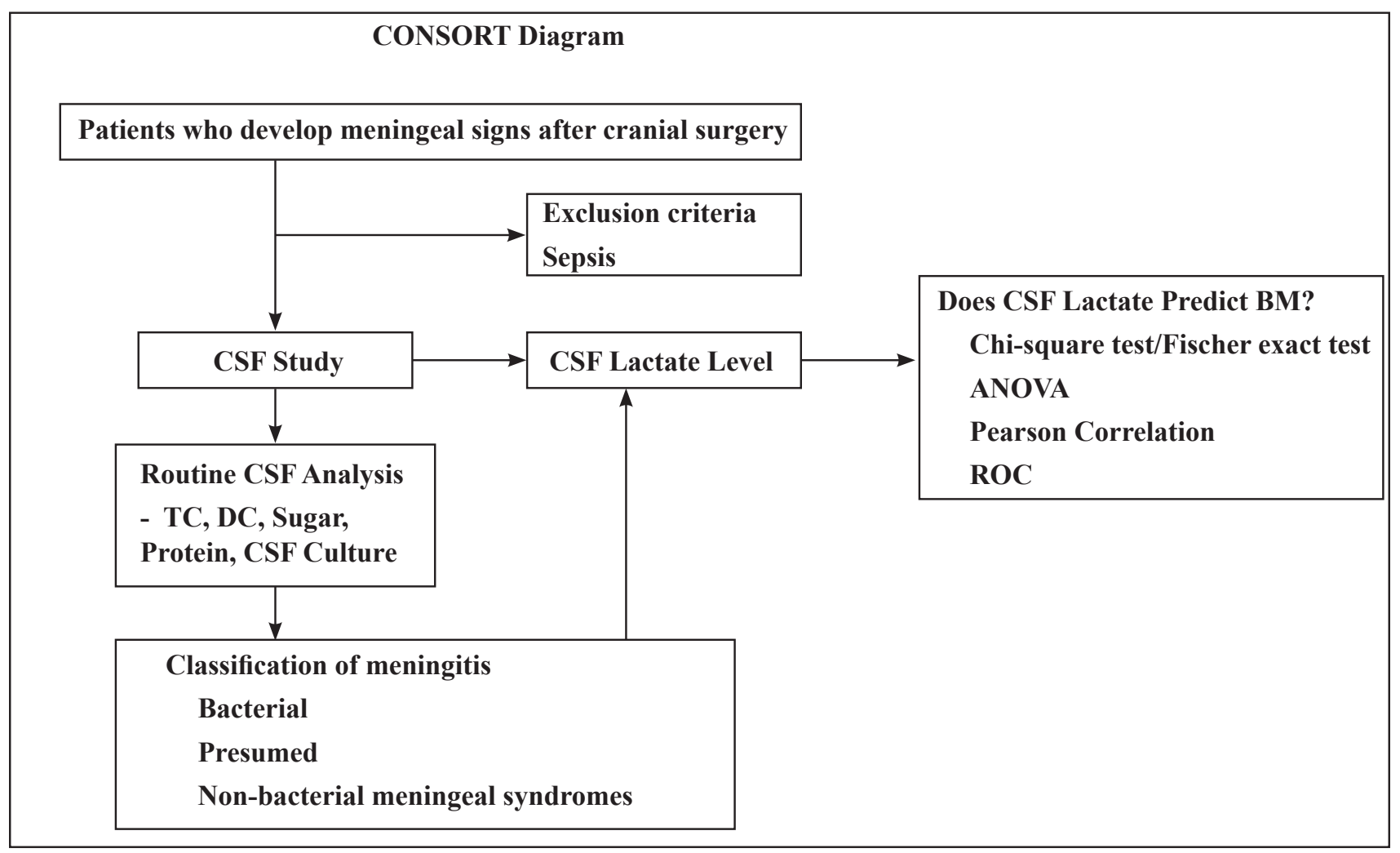

Figure 2: CONSORT diagram.

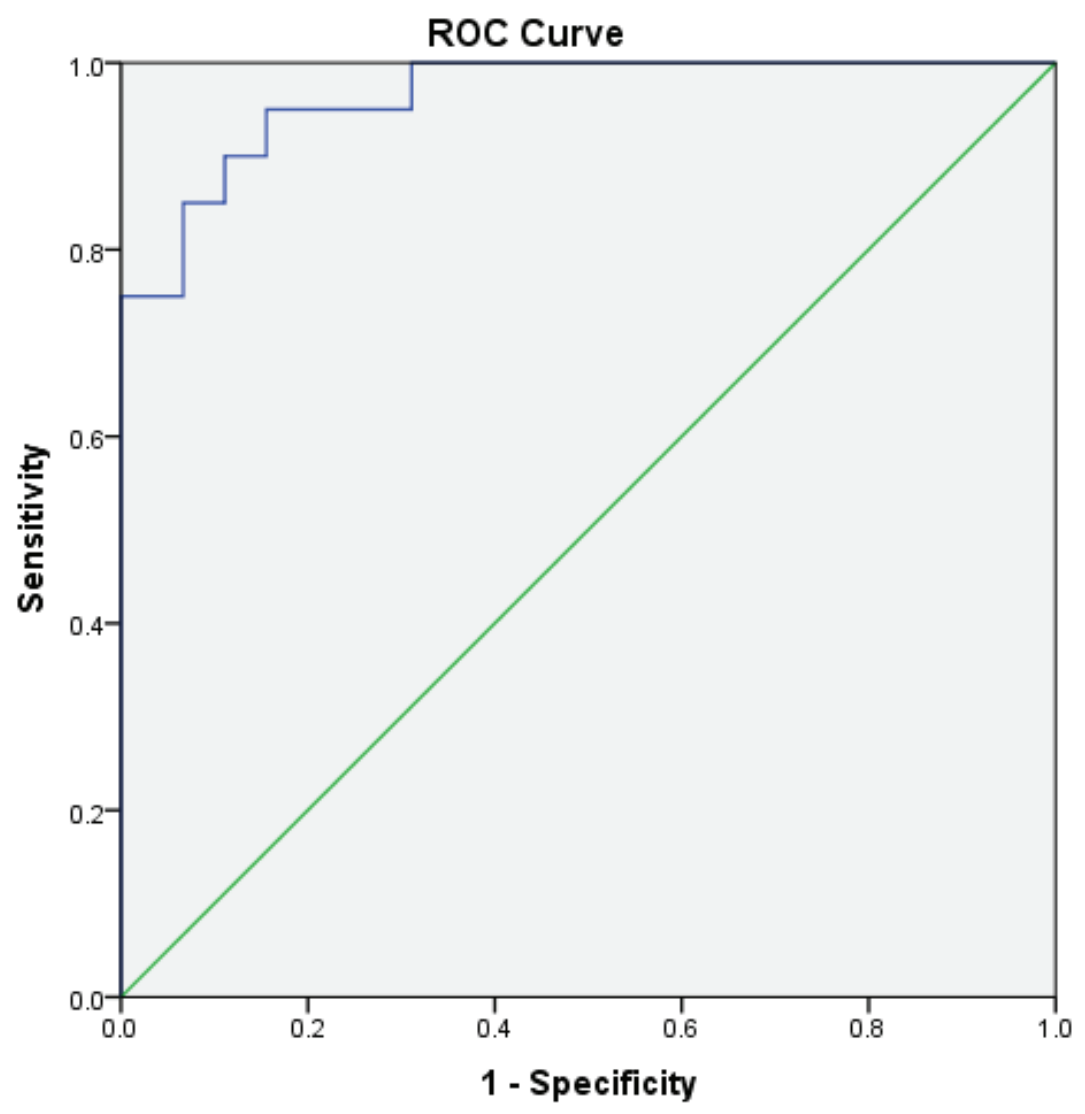

Figure 3: Area under curve. 


\section{Kharel et al}

\begin{tabular}{|c|l|c|}
\hline & \multicolumn{1}{|c}{ Type of surgery } & Frequency (n) \\
\hline 1 & VP(Ventriculo peritoneal) Shunting & 37 \\
\hline 2 & EVD(External ventricular Drain) & 9 \\
\hline 3 & ETV(Endoscopic Third Ventriculostomy) & 7 \\
\hline 5 & Shunt Revision & 5 \\
\hline 6 & VP Shunt exteriorization & 4 \\
\hline 7 & Tumor excision & 1 \\
\hline 8 & Cervical Meningomyelocele excision & 1 \\
\hline & Grand total & 1 \\
\hline
\end{tabular}

Table 1: Surgical characteristics of patients enrolled.

\begin{tabular}{cc|c}
\hline & & WBC count \\
Level of CSF lactate & Pearson correlation & $.540^{*}$ \\
& Sig. (2-tailed) & .000 \\
\hline
\end{tabular}

*correlation is significant at the 0.01 level (2 tailed)

Table 2: Relationship between WBC count and Level of lactate in CSF.

\begin{tabular}{c|c}
\hline Variable & CSF lactate level $($ Mean \pm SD) \\
\hline Bacterial Meningitis $(\mathrm{n}=20)$ & $8.4 \pm 3.0 \mathrm{mmol} / \mathrm{l}(\mathrm{p}<0.0001)$ \\
\hline Presumed bacterial meningitis $(\mathrm{n}=7)$ & $4.8 \pm 0.99 \mathrm{mmol} / \mathrm{l}(\mathrm{p}<0.005)$ \\
\hline Non Bacterial Meningitis syndrome $(\mathrm{n}=38)$ & $2.08 \pm 0.822 \mathrm{mmol} / \mathrm{l}(\mathrm{p}<0.001)$ \\
\hline
\end{tabular}

Table 3: Significance difference in types of meningitis (BM, Presumed and NBMS).

Test Result Variable(s): Level of CSF Lactate

\begin{tabular}{|c|c|c|c|c|}
\hline Area & Std. Error a & Asymptotic Sig. & \multicolumn{2}{|c|}{$\begin{array}{c}\text { Asymptotic 95\% Confidence Interval } \\
\text { Lower Bound }\end{array}$} \\
\hline .964 & .021 & .000 & .924 & 1.000 \\
\hline
\end{tabular}

a. Under the nonparametric assumption

b. Null hypothesis: true area $=0.5$

Table 4: Area under curve to show specificity.

\begin{tabular}{|c|c|c|c|c|c|c|}
\hline & Cut-off value & PPV of lactate & NPV of lactate & Sensitivity & Specificity & $\begin{array}{c}\text { Area Under } \\
\text { ROC }\end{array}$ \\
\hline Leib et $\mathrm{al}^{2}$ & $4.0 \mathrm{mmol} / 1$ & $96 \%$ & $94 \%$ & $88 \%$ & $98 \%$ & NA \\
\hline Travares et al ${ }^{28}$ & $5.4 \mathrm{mmol} / \mathrm{L}$ & $75 \%$ & $95 \%$ & $86 \%$ & $90.5 \%$ & 0.85 \\
\hline Grille et al ${ }^{29}$ & $5.9 \mathrm{mmol} / \mathrm{L}$ & $77 \%$ & $97 \%$ & $87 \%$ & $94 \%$ & 0.92 \\
\hline Maskin et al 27 & $4.0 \mathrm{mmol} / \mathrm{L}$ & $70 \%$ & $100 \%$ & $100 \%$ & $78 \%$ & 0.96 \\
\hline Li et $\mathrm{al}^{30}$ & $3.45 \mathrm{mmo} / \mathrm{L}$ & $69.2 \%$ & $95.6 \%$ & $90 \%$ & $84.4 \%$ & 0.94 \\
\hline Our study & $4.0 \mathrm{mmol} / \mathrm{L}$ & $75 \%$ & $95.12 \%$ & $90 \%$ & $87 \%$ & 0.96 \\
\hline
\end{tabular}

Table 5: Comparison of sensitivity and specificity as per various studies.

\section{Discussion}

The occurrence of bacterial meningitis after neurosurgery has been documented in up to $4 \%$ of patients. ${ }^{25,26}$ The diagnosis of BM relies on the isolation of bacteria from CSF samples. However, in up to $70 \%$ of clinically suspected cases,
Bacterial CSF cultures remain negative. ${ }^{1,4}$ The severe consequences of delayed or untreated $\mathrm{BM}$, in conjunction with the lack of clear diagnostic criteria for BM occurring after neurosurgery, explain the prevailing practice of empirically treating all suspected cases with high-dose broad spectrum intravenous antibiotics. The expense and risk of unnecessary treatment of uninfected patients 
call for a more specific test for the diagnosis of BM after neurosurgery.

The prevalence of bacterial meningitis was 20 (30.8\%). Thirty Eight (58.46\%) and 7 (10.76\%) patients were diagnosed with non-bacterial and presumed bacterial meningitis respectively as shown in the table below. This was similar to the findings in the study from Lieb et. al ${ }^{2}$ (34\%); Maskin et. $\mathrm{al}^{27}(33 \%)$ and Traveres et. $\mathrm{al}^{28}(25 \%)$. The high prevalence of the bacterial meningitis in our and several other studies may be due to the fact that study was done in patients who were clinically suspected to be meningitis. These are the high risk group of patients who were subjected to CSF analysis.

The cut off value of lactate is different in different studies ranging from $3.45 \mathrm{mmol} / \mathrm{L}$ to $5.9 \mathrm{mmol} / \mathrm{L}$. (Table 5) In our study the area under the curve in is 0.96 which is in between 0.90 and 1 that indicate the experiment has very high level of specificity and the significance level is $<.001$. the cut off point is 4.0 , the sensitivity at that point is $90 \%$ and specificity is $87 \%$. The positive predictive value is $75 \%$ and the negative predictive value is $95.12 \%$. These results are comparable to other studies shown in the table.

In study of Lieb et al, they have compared lactate level to $\mathrm{CSF} /$ blood glucose ratio and concluded that the CSF lactate level (cutoff, $4 \mathrm{mmol} / \mathrm{L}$ ) is superior to the CSF/ blood glucose ratio (cutoff, 0.4) for diagnosis of BM in neurosurgical patients. Similarly, Travares et al concluded CSF cellularity, glucose and lactate can be more reliable for the diagnosis of BM than clinical parameters alone in post neurosurgical patients while comparing different CSF markers. The study of Grille et al concluded CSF lactate represents a good marker for BM following neurosurgical procedures, superior to other biochemical or cytological CSF markers such as CSF protein, glucose and CSF/ blood glucose ratio. Maskin et al concluded CSF lactate as a reliable marker for distinguishing bacterial meningitis from aseptic meningitis. Li et al concluded that CSF procalcitonin and lactate are reliable markers to distinguish between PNBM and non-PNBM, and current sensitivity and negative predictive values are achieved with a cut-off value of $0.075 \mathrm{ng} / \mathrm{mL}$ for procalcitonin and $3.45 \mathrm{mmol} / \mathrm{L}$ for lactate. However, his study has better results with CSF lactate compared to procalcitonin.

Several other biochemical tests are under study to find a single biomarker to determine bacterial meningitis from aseptic meningitis. However, CSF lactate could be the one of the important markers to distinguish bacterial meningitis from aseptic meningitis. This can prevent the use of unnecessary antibiotics to patients who are suspected to have aseptic in preventing antibiotic resistance which is going to create a great problem in future. Those patients with high CSF lactate level must be started on empirical antibiotics to prevent and decrease the morbidity and mortality due to BM following cranial surgery

\section{Conclusion}

Our results indicate that CSF lactate is reliable to distinguish between post-neurosurgical bacterial meningitis and non-bacterial meningitis syndrome. High sensitivity and negative predictive values are achieved with a cut-off value of $4 \mathrm{mmol} / \mathrm{L}$, and this value is especially useful to rule out post neurosurgical bacterial meningitis in the adequate clinical setting.

\section{Conflict of Interest: None \\ Source(s) of support: None}

\section{References}

1. Blomstedt G.C. Infections in neurosurgery: A retrospective study of 1143 patients and 1517 operations. Acta Neurochirurgica .1985;78(3): 81-90. https://doi.org/10.1007/BF01808684

2. Leib SL, Boscacci R, Gratzl O, Zimmerli W. Predictive value of cerebrospinal fluid (CSF) lactate level versus $\mathrm{CSF} /$ blood glucose ratio for the diagnosis of bacterial meningitis following neurosurgery. Clin Infect Dis. 1999;29(1): 69-74. https://doi.org/10.1086/520184

3. Carmel PW, Greif LK. The aseptic meningitis syndrome: a complication of posterior fossa s urgery. Pediatr Neurosurg. 1993;19:(276-80). https://doi. org/10.1159/000120744

4. Ross D, Rosegay H, Pons V. Differentiation of aseptic and bacterial meningitis in postoperative neurosurgical patients, J Neurosurg .1988; 69 :66974. https://doi.org/10.3171/jns.1988.69.5.0669

5. Forgacs P, Geyer CA, Freidberg SR.Characterization of chemical meningitis after neurological surgery. Clin Infect Dis. 2001; 32(2): 179-85. https://doi. org/10.1086/318471

6. F Salord, O Boussaid,N Eynard,C Perret,J Grando,R Chacornac. Value of D (-) lactate assay for the rapid diagnosis of meningitis after craniotomy. Preliminary study. French Annals of Anesthesia and Reanimation. 1994. 13(5).647-53. https://doi.org/10.1016/s07507658(05)80720-8

7. B Genton , J.P. Berger.Cerebrospinal fluid lactate in 78 cases of adult meningitis. Intensive Care Med. 1990;16(3): 196-200. https://doi.org/10.1007/ BF01724802

8. Roland P S, Meyerhoff W L, Balcombe KL,Mickey B E . Spinal fluid profile following surgery in the subarachnoid space. Otolaryngol Head Neck Surg.1989; 101(4): 445-8. https://doi. org/10.1177/019459988910100407

9. J Eross, M Silink, and D Dorman.Cerebrospinal fluid lactic acidosis in bacterial meningitis. Arch Dis 
Child. 1981; 56(9): 692-8. https://doi.org/10.1136/ adc.56.9.692

10. J Tureen. Effect of recombinant human tumor necrosis factor-alpha on cerebral oxygen uptake, cerebrospinal fluid lactate, and cerebral blood flow in the rabbit: role of nitric oxide. Journal of Clinical Investigation. 1995; 95(3): 1086-1091. https://doi. org/10.1172/JCI117755

11. S L Leib, Y S Kim, L L Chow,R A Sheldon,M G Tauber .Reactive oxygen intermediates contribute to necrotic and apoptotic neuronal injury in an infant rat model of bacterial meningitis due to group B streptococci. J Clin Invest.1996; 98(11): 2632-9. https://doi.org/10.1172/JCI119084

12. Leib S L, Kim YS, Black SM ,Tureen JH,Tauber MG. Inducible nitric oxide synthase and the effect of aminoguanidine in experimental neonatal meningitis. J Infect Dis.1998; 177(3): 692-700. https://doi. org/10.1086/514226

13. Bogdan I, Leib SL, Bergeron M, Chow L, Tauber MG. Tumor Necrosis Factor- $\alpha$ Contributes to Apoptosis in Hippocampal Neurons during Experimental Group B Streptococcal Meningitis. Journal of Infectious Diseases.1997; 176(3): 693-697. https://doi. org/10.1086/514092

14. Cameron P D, J M Boyce, B M Ansari. Cerebrospinal fluid lactate in meningitis and meningococcaemia. J Infect.1993;26(3): 245-52. https://doi. org/10.1016/0163-4453(93)95253-f

15. Tauber M G, U Borschberg, M A Sande.Influence of granulocytes on brain edema, intracranial pressure, and cerebrospinal fluid concentrations of lactate and protein in experimental meningitis. J Infect Dis, 1988. 157(3): 456-64. https://doi.org/10.1093/ infdis/157.3.456

16. Van de Beek D, J M Drake, A.R. Tunkel. Nosocomial bacterial meningitis. N Engl J Med. 2010; 362(2): 146-54. https://doi.org/10.1056/NEJMra0804573

17. Cunha B A.Distinguishing bacterial from viral meningitis: the critical importance of the CSF lactic acid levels. Intensive Care Medicine. 2006; 32(8): 1272-3 https://doi.org/10.1007/s00134-006-0210-x

18. K Bromberg. Lactate Concentrations in Cerebrospinal Fluid. J Infect Dis. 1980; 142(2): 307-309. https://doi. org/10.1093/infdis/142.2.307

19. Ruuskanen O, M L Stahlberg,H Korvenranta,K Irjala. CSF lactate in bacterial meningitis with minimal CSF abnormalities. Acta Paediatr Scand.1985;74(2): 292-3. https://doi.org/10.1111/j.1651-2227.1985. tb10968.x

20. Rajs G,Zvesdana finji-Yeheskel,andreas Rajs,Michael Mayer. C-reactive protein concentrations in cerebral spinal fluid in gram-positive and gram- negative bacterial meningitis. Clinical Chemistry. 2002;48(3):591-2. PMID: 11861461

21. Viallon A, Pouzet V,Zeni F, Tardy B, Guyomarch S,Lambert C, Page Y,Bertrand JC. Rapid diagnosis of the type of meningitis (bacterial or viral) by the assay of serum procalcitonin(Article in French). Presse Med. 2000; 29(11): 584-8. PMID: 10776411

22. Linder A, Akesson P, Brink M, Studahl M, Björck L, Christensson B. Heparin- binding protein: a diagnostic marker of acute bacterial meningitis. Crit Care Med. 2011;39:812-7 https://doi.org/10.1097/ CCM.0b013e318206c396

23. Knudsen TB, Larsen K, Kristiansen TB, Møller HJ, Tvede M, Eugen-Olsen J, et al. Diagnostic value of soluble CD163 serum levels in patients suspected of meningitis: comparison with CRP and procalcitonin. Scand J Infect Dis. 2007;39:542-53. https://doi. org/10.1080/00365540601113685

24. Bland R D, R C Lister, J.P. Ries. Cerebrospinal fluid lactic acid level and $\mathrm{pH}$ in meningitis. Aids in differential diagnosis. Am J Dis Child. 1974;128(2): 151-6. https://doi.org/10.1001/ archpedi.1974.02110270025006

25. Narotam PK, J R van Dellen,M D du Trevou,E Gouws . Operative sepsis in neurosurgery: a method of classifying surgical cases. Neurosurgery. 1994;34(3): 409-15. https:// doi.org/10.1227/00006123199403000-00004.

26. Jacobs D G, A. Westerband. Antibiotic prophylaxis for intracranial pressure monitors. Journal of the National Medical Association.1998; 90(7): 417-23. PMID: 9685777

27. LP Maskin, Capparelli F, Mora A, Hlavnicka A,Orellana N, Díaz MF, Del Castillo M. Cerebrospinal fluid lactate in post-neurosurgical bacterial meningitis diagnosis. Clinical Neurology and Neurosurgery.2013; 115(9):1820-5. https://doi. org/10.1016/j.clineuro.2013.05.034

28. Tavares WM, Machado AG, Matushita H, Plese JP. CSF markers for diagnosis of bacterial meningitis in neurosurgical postoperative patients. Arq Neuropsiquiatr. 2006;64(3A):592-5. https://doi. org/10.1590/s0004-282x2006000400012

29. Grille P, Torres J, Porcires F, Bagnulo H. Value of cerebrospinal fluid lactate for the diagnosis of bacterial meningitis in postoperative neurosurgical patients. Neurocirugia. 2012;23(4):131-5. https://doi. org/10.1016/j.neucir.2011.11.005

30. Li Y, Zhang G, Ma R, Du Y, Zhang L, Li F, et al. The diagnostic value of cerebrospinal fluids pro calcitonin and lactate for the differential diagnosis of post-neurosurgical bacterial meningitis and aseptic meningitis. Clin Biochem. 2015;48(1-2):50-4. https://doi.org/10.1016/j.clinbiochem.2014.10.007 